\title{
Corrigendum: Osteomyelitis Treated with Antibiotic Impregnated Polymethyl Methacrylate
}

Hsueh-Yu Li, Kyu-Ho Yoon, Kwan-Soo Park, Jeong-Kwon Cheong, Jung-Ho Bae, Jung-Gil Han, Hyung-Koo Park, Jae-Myung Shin, Ji-Sun Baik

J Korean Assoc Maxillofac Plast Reconstr Surg 2013;35(6):396-401

http://dx. doi.org/10.14402/jkamprs. 2013.35.6.396

In published article by Li et al., an author's name was misspelled. The authors would like to correct the author's name as follow;

Hsueh-Yu Li, Kyu-Ho Yoon, Kwan-Soo Park, Jeong-Kwon Cheong, Jung-Ho Bae, Jung-Gil Han, Hyung-Koo Park, Jae-Myung Shin, Jee-Seon Baik

We sincerely apology for any inconvenience it may cause.

Correspondence to Jung-Ho Bae

Department of Oral and Maxillofacial Surgery, Inje University Sanggye Paik Hospital

1342 Dongil-ro, Nowon-gu, Seoul 139-707, Korea

Tel: 82-2-950-1161, Fax: 82-2-950-1167, E-mail: bgeneral@paik.ac.kr

Copyright (C) 2014 by The Korean Association of Maxillofacial Plastic and Reconstructive Surgeons. All rights reserved.

(c) This is an open access article distributed under the terms of the Creative Commons Attribution Non-Commercial License (http://creativecommons. org/licenses/ by-nc/3.0) which permits unrestricted non-commercial use, distribution, and reproduction in any medium, provided the original work is properly cited. 